\title{
HERMENÉUTICA Y GRAMÁTICA BAJO LOS ALMOHADES: IBN JARŪF Y LOS TESTIMONIOS TARDÍOS
}

\author{
SAlVAdOR PeÑa MARTíN \\ Universidad de Málaga
}

Los gramáticos árabes medievales ${ }^{1}$ tenían como objeto de interés un estado de lengua bien determinado, el kalām al- 'arab o lengua de los árabes «puros», que venía a coincidir con el árabe usado en el $\mathrm{Co}$ rán. Tal estado de lengua tenía su razón de ser, según los gramáticos, en que sus hablantes, los 'arab, se expresaban según su natural y sin influencia de otros idiomas que hubiesen podido alterar su lengua. De modo que quedaban excluidos de la descripción y de la argumentación los dichos (o escritos) de los muwalladūn, esto es, de los árabes «mestizos», que, por haberse mezclado con otros pueblos, se expresaban en una lengua afectada de corrupción $(f a s \bar{a} d)$. Y se consideraba que la corrupción que invalidaba los testimonios de los hablantes se produjo en torno al siglo II de la hégira/VIII después de Cristo para los habitantes de las ciudades, y al IV/X para los beduinos del desierto. Este principio metodológico se mantuvo firme desde que al-Jalīl y Síbawayhi fundaron los estudios gramaticales árabes ${ }^{2}$, o sea, la descripción de las reglas fonológicas y morfosintácticas tal como se ha ido llevando a cabo durante siglos. Y de dicho principio: que el corpus de la lengua árabe lo integraban solamente los dichos de los árabes «puros», deriva una serie de consecuencias prácticas: 1) a partir de los siglos indicados los gramáticos dejaron de utilizar la encuesta lingüística, por falta de hablantes competentes; 2) la elaboración de las reglas gramaticales, por medio de la analogía, no tuvo otra base posible que el corpus ya recogido y cerrado, y 3) los testimonios

\footnotetext{
1 Agradezco a Jorge Lirola Delgado que me haya facilitado una copia del libro de Ibn Jarūf estudiado aquí; a Elisa A. Peña Alonso y Miguel Vega Martín, que hayan disipado mis dudas sobre ciertos términos jurídicos y teológicos, $\mathrm{y}$ a Maribel Fierro y Delfina Serrano sus valiosos comentarios al último borrador del presente escrito.

$2 \mathrm{Y}$ asimismo los léxicos (luga), para los que también valen las restricciones metodológicas sobre las pureza de los 'arab a las que acabamos de referirnos.
}

Al-Qanțara XXVI, 2 (2005) 371-380 
(šawāhid), que servían a la inducción de reglas y procuraban ilustraciones en los libros de gramática, no podían nunca proceder de hablantes «mestizos» ${ }^{3}$.

Este importante fundamento de la gramática árabe medieval no ha recibido de la historiografía lingüística contemporánea la atención que merece. Apenas contamos con algún estudio que aborde de modo comprensivo el asunto de los testimonios en gramática, incluyendo cierta leve desviación del principio de invalidez de los hablantes «mestizos» ${ }^{4}$. El paso adelante respecto del principio metodológico establecido, esa leve desviación, lo dieron, por una parte y en el extremo occidental del mundo islámico, Ibn al-Sīd al-Bațalyawsī (m. 521 h./1127 d.C.), a quien podemos considerar el mayor filólogo y lingüista de al-Andalus, y la valoración de cuya obra, en materia de lengua, textos y hermenéutica parece ya estar produciéndose, más allá de su incursión en la filosofía s; $y$, por otra, en Oriente, su contemporáneo Abū 1-Qäsim al-Zamajšarī (m. 538/1144), el gramático y exegeta mu'tazilí ${ }^{6}$.

Dicha innovación consistía, en ambos casos, en la aducción de testimonios de hablantes tardíos, y por tanto «mestizos», como argumentos gramaticales. En el caso de al-Zamajšarī, se trataba de un verso de Abū Tammām (m. 231/845), a quien el gramático oriental consideraba autoridad en materia lingüística en virtud del siguiente razonamiento: Abū Tammām fue un gran antólogo de poesía árabe «pura» (en su antología Al-Hamāsa); por tanto, podemos considerarlo un gran conocedor de ésta; así que sus propios versos, obra de un experto en árabe «puro», son admisibles como testimonios. Y, con esta

${ }^{3}$ Sobre todo esto, v. 'Umar, A.M., Al-Baht al-lugawi' ind al- 'arab, El Cairo, 1982, 1953; Peña Martín, S., La obra lingüistica y filológica de Ibn al-Síd al-Batalyawsī, Tesis Doctoral, Universidad de Granada, 1987, 58-134, y Ferrando, I., Introducción a la historia de la lengua árabe: Nuevas perspectivas, Zaragoza, 2001, 117-133.

4 V. Peña, S., «El corpus de los lingüistas musulmanes y la noción de autoridad», Miscelánea de Estudios Árabes y Hebraicos XXXVII, 1 (1988), 195-209, y Gilliot, C., «Les citations probantes (šawāhid) en langue», Arabica XLIII (1996), 297-336.

5 V. Codera, F., Decadencia y desaparición de los almorávides en España, Zaragoza, 1899, 347-53; Asín Palacios, M., «Ibn al-Sīd de Badajoz y su «Libro de los cercos» (Kitāb al-Hadā'iq)», Al-Andalus V (1940), 45-154; Peña, S., Ma 'arrĩ según Batalyawsĩ: Crítica y poética en al-Andalus, siglo XI, Granada, 1990, y Serrano, D., «Ibn al-Sīd al-Batalyawsī (444/1052-521/1127): de los Reinos de Taifas a la época almorávide a través de la biografia de un ulema polifacético», Al-Qanțara XXIII (2002), 53-92.

6 V. al-Ḥawfi, A.M., Al-Zamajšari, El Cairo, s.d., y Agius, D.A., «Some bio-biographical notes on Abū 'l-Qāsim Maḥmūd b. 'Umar al-Zamajšarì), Al- 'arabiyya 15 (1982), 108-30. 
justificación, al-Zamajšarī se atreve a citar a Abū Tammām nada menos que en su obra de exégesis coránica ${ }^{7}$. En un razonamiento semejante se basa Ibn al-Sīd, quien recurre, por una parte, a versos de Abū Tammām, Ibn al-Rūmī (m. 283/896), Ibn al-Mu'tazz (m. 296/908) y al-Mutanabbī (m. 354/965), de este último en varias ocasiones ${ }^{8}$. Y, por otra, a fragmentos de varios prosistas, también inválidos como informantes según la restricción de la «pureza», por ser tardíos o mestizos o ambas cosas a la vez ${ }^{9}$ : Sỉbawayhi (m. 177/793), al-Mubarrid (m. 286/899), Abū 'Alī al-Fārisī (m. 377/987) y al-Hamad̄ānī (m. 388/1077). Si este asunto, el de las citas de hablantes tardíos, apenas ha suscitado interés entre los historiadores de la lingüística árabe, éstos tampoco han reparado, que sepamos, en que esa misma innovación metodológica la mantuvo otro gramático en el Occidente islámico de los almohades.

En efecto, el andalusí Ibn Jarūf ${ }^{10}$ (m. ca. 609/1212) recurrió también a testimonios tardíos para la descripción gramatical. Y lo hizo en su comentario a Al-Ŷumal, el célebre manual de gramática de al-Zaŷŷâŷ̀ (m. ca. 340/951), que tanta labor escolástica generó en el Occidente islámico ${ }^{11}$. Siguiendo, pues, la estela de Ibn al-Sĩd, el sevillano (tal vez rondeño de origen) Ibn Jarūf utiliza en su Šarh Ŷumal I, 87.

${ }^{7}$ Al-Kaššăf 'an haqā'iq al-tanzìl wa- 'uyūn al-aqãwīl fî̀ wuŷū'h al-ta'wīl, Beirut, s.d.,

${ }^{8}$ Kitāb al-Masā'il wa-l-aŷwiba, ms. Escorial (Derenbourg, n. $\left.{ }^{\circ} 1518\right), 60 \mathrm{a}, 48 \mathrm{a}$ y b. Y v. también Al-Iqtiḍāb fi šarh Adab al-kuttāb, ed. al-Saqqā, M. y 'Abd al-Maŷĩd, H.., El Cairo, 1981-83, I, 30, donde Ibn al-Sīd justifica, de modo similar al de al-Zamajšarī respecto a Abū Tammām, su empleo de versos de al-Mutanabbī como testimonios.

9 Este asunto se trata con detalle en Peña, S. «El corpus de los lingüistas», 205-6.

10 V. Ibn 'Abd al-Malik al-Marrākušī, Al-Dayl wa-l-takmila li-kitābay al-Mawșūl wa-l-Sila, ed. 'Abbās, I., Beirut, 1965, V, 319-22 (n. ' 635), entre las varias fuentes biográficas que de él se ocupan.

11 Se ha afirmado que de $\mathrm{Al}$-Ŷmal se escribieron en al-Andalus y el Mágreb unos ciento veinte comentarios. Uno de los más antiguos en la Península fue el de Ibn al-'Arï (m. 390 = 999-1000); posteriormente hubo grandes figuras que se ocuparon sólo de los versos, como hicieron Ibn Sĩdah (m. 458/1066) o al-A'lam al-Šantamārī (m. 476/1083). Más tarde el libro fue comentado por los dos gramáticos más sobresalientes de al-Andalus en época almorávide: Ibn al-Sĩd e Ibn al-Tarāwa (m. 528/1134); cuyas contribuciones tuvo muy en cuenta Ibn Jarūf en la suya. Fue precisamente en la época de éste, durante los siglos VI-VII = XII-XIII, cuando más proliferaron los comentarios a Al-Ŷmal en al-Andalus. Ibn Hišām al-Lajmī (m. ca. 570/1174), al-Suhaylī (m. 581/1185-6), Ibn al-Ḍā'i' (m. 680/1281) e Ibn 'Ušfür (m. 669/1271), que escribió nada menos que tres, se cuentan entre los contemporáneos de Ibn Jarüf que hicieron como él con el manual oriental. El movimiento se prolongó bien avanzada la época nazarí, pero eso ya no nos afecta aquí. V., sobre lo anterior, Peña, S., La obra lingüística y filológica, 432 y ss. 
al-Zâŷyâŷt ${ }^{12}$, y siempre en la argumentación gramatical, versos de Abū Nuwās y de Abū Tammām, cuyos nombres no declara, limitándose a hablar de «lo que dijo el poeta»; pero también, en una ocasión, de al-Mutanabbī, a quien sí nombra. Detengámonos en esta cita explícita de un testimonio debido a un poeta tardío ${ }^{13}$, que vivió en medios urbanos durante el siglo IV de la hégira, de manera que se trata de un hablante «mestizo», que hablaría un árabe «corrupto», si nos atenemos a los fundamentos que expusimos al principio. Pues bien, la cita aparece ${ }^{14}$ al tratarse la partícula exclamativa $W \bar{A}$ - ('¡ay!, iqué!’) de conmiseración (nudba), cuyo uso ilustra Ibn Jarūf con una exclamación atribuida al califa 'Umar b. al-Jațāāb (m. 23/644), a quien, por supuesto, sí podemos considerar hablante de árabe «puro», y un hemistiquio de al-Mutanabbī:

Wā harra qalbā-hu mim-man qalbu-hu šabimu (“¡Qué corazón tan caliente para un corazón helado!').

No se trata, desde luego, de una ruptura absoluta con la metodología de la argumentación por medio de testimonios (istišhād), puesto que las palabras de al-Mutanabbī vienen a unirse al šăhid (árabe «puro») del califa 'Umar ${ }^{15}$. Pero, por eso mismo, la introducción de un hemistiquio de un poeta tardío y urbano es de todo punto innecesaria y sorpresiva desde la perspectiva usual. Téngase en cuenta que Ibn Jarūf podría haber recurrido a algún testimonio poético «puro», si es que lo consideraba oportuno, como los que incluye Sibawayhi al tratar de esta misma cuestión gramatical ${ }^{16}$; $\mathrm{y}$, asimismo, que ni el gramático comentado, al-Zaŷŷâŷ̄i, incluyó ilustración o testimonio algunos al respecto en su manual ${ }^{17}$, ni Ibn al-Sīd, a cuya contribución está muy atento Ibn Jarūf, trató las exclamaciones conmiserativas en su

12 Šarh Ŷumal al-Zaŷŷâŷy, ed. 'Arab, S.M.'U., Ŷāmi'at Umm al-Qurà, 1418 h.

13 Una sugestiva introducción a la figura del poeta la ofreció E. García Gómez, «Mutanabbi, el mayor poeta de los árabes (915-965)», Escorial III (1941), 15-49, escrito reproducido en Cinco poetas musulmanes: biografias y estudios, Madrid, 1959², 15-65.

14 Šarh Ŷumal al-Zaŷŷâŷì, II, 710.

15 Se trata de cierta exclamación del califa: Wã-'aŷabā min-ka yā [I]bna l-'Ās ('iAy de ti, Ibn al-'Ās!').

${ }^{16}$ Kitāb Sībawayhi, ed. Hārūn, 'A.S.M., Beirut, s.d., II, 220 y ss. V., además, al-Mubarrid, Kitäb al-Muqtadab, ed, 'Aḍima, M.'A.J., El Cairo, 1399 h., IV, 268 y ss., donde, al igual que en el Kitäb, la argumentación se construye más a partir de ilustraciones ficticias que sobre testimonios registrados.

17 Al-Ŷumal, ed. Ibn Abī Šanab, M., París, 1957, 190-1. 
comentario a Ŷumal ${ }^{18}$. Hemos de considerar, pues, que Ibn Jarūf está llevando a la práctica, y con determinación, una actuación metodológica de mucho relieve, por más que contase con el precedente, que probablemente conocía, de Ibn al-Sīd.

Este inusual proceder de Ibn Jarūf es aún difícil de valorar en la historia de la filología en el Occidente islámico, dados nuestros conocimientos. Pero nos ofrece indicios claros acerca de una de las vías por donde podría ir la investigación en torno a la gramática y, más ampliamente, a la vida intelectual bajo los almohades, lo que se ha llamado la revolución cultural de los almohades. Dicha revolución ha sido recientemente estudiada por M. Fierro en sus aspectos jurídi$\cos { }^{19}$. Pero seguimos sin saber cómo afectó al otro sector de las ciencias islámicas interpretativas: la gramática y la filología. El asunto, no obstante, fue hace décadas suscitado en nuestro ámbito por E. García Gómez, cuando acogió con entusiasmo cierto opúsculo polémico, el Kiāb al-Radd 'alà l-nuhāt ${ }^{20}$ (Libro de la contestación a los gramáticos) de Ibn Maḍā' (m. 592/1196), en el que vio una valiosa respuesta, de orden religioso, contra lo que habrían sido desviaciones propias de alfaquíes y de orientales ${ }^{21}$ :

La última característica de la revolución almohade es su ardiente búsqueda del hontanar de la pura espiritualidad y su guerra a muerte contra los trampantojos de los alfaquíes casuístas, esterilizadores y farisaicos. Pero también en la gramática hay alfaquíes. Ibn Madá de Córdoba arremete contra ellos para raer de la filología árabe cuanto es faramalla y vegetación parásita, y enfrentarse con las realidades lingüísticas tal como se dan efectivamente.

18 Ibn al-Sīd al-Bațalyawsī, Kitāb al-Hulal fì iṣlāḥ al-jalal min Kitāb al-Ŷumal, ed. Sa'ūdī, S.'A.K., Bagdad, 1980.

19 V., sobre todo, «The legal policies of the Almohad caliphs and Ibn Rushd's Bidāyat al-mujtahid», Journal of Semitic Studies 10:3 (1999), 226-48.

${ }^{20}$ Ed. Dayf, Š., El Cairo, $1982^{2}$.

${ }^{21}$ García Gómez, E., «La gramática y la Giralda», $A B C, 23$ de noviembre de 1947, reproducido en Silla del Moro y nuevas escenas andaluzas, Buenos Aires, 1954, 151-3, de donde tomo la cita (153). Una visión cercana a la de García Gómez la ofrece Ramón Guerrero, A., El cordobés Ibn Madāa (1119-1196) y la reforma de la gramática árabe, Universidad de Granada, 1984; en tanto que, por los mismos años, se inició una valoración del gramático cordobés desde otra perspectiva, pero sin que todavía se haya llegado, que sepamos, a conclusiones definitivas. V., a este último respecto, As'ad, 'A.K., «Hawāmiš muta-

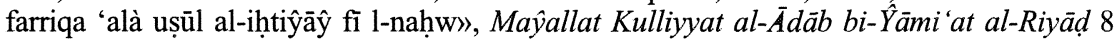
(1981), 293-327, y, sobre todo, Carter, M.G., «Linguistic science and orthodoxy in conflict: the case of ar-Rummānī», Zeitschrift für Geschichte der Arabisch-Islamischen Wissenschaften 1 (1984), 212-32. Para una breve y acertada caracterización de Ibn Madā' y de su significado, v. Ferrando, I., Introducción a la historia de la lengua árabe, 123. 
A Ibn Maḍā' podemos, desde luego, considerarlo adherido al movimiento almohade. En Tĩnmāl llegó a darles clase a los hijos del califa 'Abd al-Mu'min 22, y el tercer califa, al-Mansūr, lo puso al frente de la máxima dignidad judicial ${ }^{23}$. El propio Ibn Madā' deja clara su vinculación a la causa de Ibn Tūmart y a la dinastía mu'miní en la introducción al Kitāb al-Radd 'alà l-nuḥāt, escrito en tiempos de al-Manșūr, al confesar la impecabilidad del Mahdi y al afirmar que sus sucesores, los tres primeros califas (los dos nombrados y Abū Ya'qūb Yūsuf) eran «herederos de la grandiosa posición» del Mahdī ${ }^{24}$, entrando así en el debate, palpitante para los Mu'miníes, sobre el carisma que habría pasado del «mesías» fundador del movimiento a la dinastía que reinó en su nombre. Tenemos, de este modo, dos hechos sentados: 1) Ibn Maḍā' es un portavoz, y acaso artífice, destacado del discurso oficial almohade, y 2) formuló una crítica a ciertos aspectos del método seguido por los gramáticos representantes de la corriente, que, iniciada por los «imames» de Basora y Cufa, se actualizó en Bagdad en el siglo IV/X y alcanzó en al-Andalus su máxima expresión con Ibn al-Sĩd.

Pero la comprensión plena de la propuesta de Ibn Maḍā' exige que se tengan en cuenta no sólo sus aspectos ideológicos en el marco de la revolución almohade, sino, por un lado, el estado de los estudios gramaticales hasta su tiempo, y, por otro, su intento de verter en la gramática sus principios como teórico del derecho, sobre todo en materia de fuentes jurídicas. De manera que, cuando nos preguntemos por el empeño de Ibn Maḍā' por cercenar las cuestiones a las que debe responder el gramático, habrá que buscar la explicación combinando elementos de esos tres ámbitos:

1) La sacralización de todas las manifestaciones del Estado teocrático almohade, lo que incluía poner el saber al servicio de la propia causa y el intento de sentar unas nuevas bases de organización jurídica.

2) La posición de los zāhiríes ${ }^{25}$ (como el propio Ibn Maḍā'), que, enfrentados con las otras escuelas de hermenéutica, pretendían ${ }^{26}$ limitar el ejercicio de la

22 Fierro, M., «The legal policies», 234.

23 Ramón Guerrero, A., El cordobés Ibn Maḍā', 19-20.

${ }^{24}$ Kitāb al-Radd, 71

25 Una excelente exposición condensada de los principios zāhiríes la ofrece Adang, C., «Ibn Hazm on homosexuality: a case-study of zāhirī legal methodology», Al-Qanțara XXIV, 1 (2003), 5-35 (v. 12-14).

${ }^{26}$ La posición contraria de los primeros califas almohades ante el mālikismo y su apoyo al zāhirismo los expone Fierro, M. «The legal policies», 234 y ss. 
analogía (qiyās) y la opinión ( $r a^{\prime} y$ ), en lo que costituyó un ataque frontal a la interpretación activa, así como el uso de la jurisprudencia (taqlid), lo que suponía invalidar la interpretación acumulada.

3) La concepción, mantenida en la práctica por muchos, como Ibn Jarūf, de que los gramáticos han de reflexionar sin limitaciones sobre el lenguaje, contra la que se vuelve Ibn Maḍā'; antes de quien hubo ya sabios que lanzaron propuestas simplificadoras de la gramática, como es el caso del andalusí al-Zubaydī (m. 379/989) ${ }^{27}$.

De manera que, al abordar el estado de la filología y la gramática bajo los almohades, no basta con considerar la propuesta de Ibn Madā', quien, al menos en su Kitāb al-Radd 'alà l-nuhât, no acometió la tarea de revisar desde los cimientos la metodología de los gramáticos; de ahí que no tratase ni la cuestión de los testimonios tardíos ni otras muchas, fundamentales. Respecto a ese punto concreto de la cita de šawāhid «mestizos», cabría tal vez aventurar que la actuación de al-Zamajšarī, Ibn al-Sīd e Ibn Jarūf, consistente en conceder valor probatorio a dichos de hablantes tardíos, estaría en contra del abandono del $r a$ 'y ('opinión') por los juristas zāhiríes, pues supone admitir en hablantes tardíos la capacidad de expresarse como árabes «puros» gracias al conocimiento adquirido. Aunque precisamente el ataque al argumento de autoridad y, por tanto, la omisión de uso de la jurisprudencia, supone valorar en mucho, si bien por otro camino, la labor del sabio tardío, que puede prescindir de los doctores y enfrentarse solo a las fuentes. Pero esto es internarse en un terreno inexplorado.

La profundización en la historia de la gramática bajo los almohades exige, como es lógico, que se considere la obra de otros sabios del lenguaje y el texto, también vinculados a las élites almohades, tales como Abū 1-'Abbās al-Šarīšī (m. 620/1222), quien declaró explícitamente su adhesión al régimen instaurado por los Mu'miníes ${ }^{28}$. $\mathrm{O}$, asimismo, que contemos con la labor de otros sabios, tal vez menos afectos al estado de cosas instaurado por los seguidores del alfaquí y «mesías» Ibn Tūmart (m. 524/1130), como fue seguramente el caso de Ibn Jarūf, quien vivió ambulante por al-Andalus y el Norte de África, alternando, como medio de vida, la enseñanza de la gramática con

27 En su manual de gramática Kitāb al-Wādihh, ed. Jalīfa, 'A.K., Jordania [sic], 1976.

28 En la introducción a su Šarh Maqāmāt al-Harîrī al-Bașrī, ed. Ŷamīl, S.M., Beirut, s.d., 9-14. Sobre al-Šarī̌̄īi, como estudioso del léxico, v. Arias Torres, J.P., Estudios léxicos en al-Andalus (siglo VI h./XII c.), Tesis doctoral, Universidad de Granada, 1995. 
la fabricación y venta de utensilios de madera ${ }^{29}$, lo cual permite concluir que mantuvo cierta distancia con los cuadros de mando mu'miníes, a diferencia de Ibn Maḍā'. Aunque es cierto también que Ibn Jarūf contó, al menos circunstancialmente, con el mecenazgo de los Mu'miníes, pues el cuarto califa, al-Nāșir, lo premió con una elevada suma de dinero por uno de sus libros, su comentario al Kitāb de Sỉbawayhi ${ }^{30}$.

El cuadro que va formándose ante nosotros gana precisión con el dato ${ }^{31}$ de cierta polémica que mantuvieron ambos gramáticos, Ibn Jarūf e Ibn Maḍā'. El último fue autor de un escrito en que, a juzgar por su título y en consonancia con lo que expone en su Kitāb al-Radd 'alà l-nuhāt, pretendía mostrar cómo el texto del Corán está exento de cualquier falta contra la claridad expositiva (bayān); a ello respondió Ibn Jarūf con otro escrito donde defendía a los doctores (a 'imma) de la gramática de los errores y omisiones que algunos les atribuían ${ }^{32}$. La materia de discusión: el propio texto de la palabra revelada por Dios ante los hallazgos de los gramáticos es indicativo del ámbito en el que se movían los dos sabios. Como es significativo el desdeñoso juego de palabras a partir del nombre de Ibn Jarūf (literalmente, «el Hijo del Cordero») con que Ibn Maḍā' acogió la respuesta de éste: «No nos han preocupado los carneros mejor armados, y ahora nos salen al paso los hijos de los corderos...». Ése no fue el único enfrentamiento de Ibn Jarūf con otros gramáticos andalusíes; como tampoco lo fue por parte de Ibn Maḍā', quien, en su Kitāb al-Radd 'alà l-nuhāt, critica abiertamente a los andalusíes al-A'lam al-Šantamarī (m. 476/1083) y a su contemporáneo Abū 1-Qāsim al-Suhaylī (581/1185-6), relacionado asimismo con la dinastía mu'miní, pues fue preceptor de los hijos de Abū Ya'qūb Yūsuf ${ }^{33}$. Estas polémicas entre gramáticos, que venían siendo usuales en épocas anteriores, parecen indicio de que también en época almohade la filología seguía ofreciendo múltiples y graves puntos para el debate.

29 Ibn 'Abd al-Malik, Al-Dayl wa-l-takmila, $V, 321$

30 Ibidem, donde se especifica la cantidad: cuatro mil dírhames.

31 Ŷalāl al-Dīn al-Suyūṭ̂i, Bugyat al-wu'àt fì țabaqāt al-lugawiyyīn wa-l-nuhāt, ed. Ibrāhīm, M.A.F., Beirut, 1979², I, 323.

${ }^{32}$ Los dos escritos llevaban los títulos siguientes: el de Ibn Madā', Tanzīh al-Qur'ān 'am-mā lā yalīqu bi-l-bayān, y el de Ibn Jarūf, Tanzīh a'immat al-naḥw 'am-mã nusib ilay-him min al-jata' wa-l-sahw.

${ }^{33}$ Arias Torres, J.P., Estudios léxicos, 43. 
Recapitulemos. Que Ibn Jarūf cite como testimonio gramatical un hemistiquio de al-Mutanabbĩ es, en sí mismo, un hecho reseñable, y que habrá que valorar debidamente en la historia de la gramática en al-Andalus. Para ello será necesario tener en cuenta que Ibn Jarūf no está sino llevando adelante una propuesta metodológica de Ibn al-Sìd, el alfaquí de la época de los almorávides, con la cual no se produce, pues, ruptura en este ámbito. ¿Quiere esto decir que la revolución almohade no afectó en nada a la evolución de los estudios gramaticales en el Occidente islámico? Aún no estamos en condiciones de poder responder a una pregunta como ésta. Para hacerlo, habrá que considerar que los dos frentes de actividad intelectual considerados aquí, el jurídico y el filológico, incluida la gramática, comparten, como hemos dicho, un mismo ámbito, el de la interpretación (hermenéutica). No hace mucho M. Fierro tradujo el título de uno de los libros cardinales en la constitución del discurso almohade, la Bidāyat al-muŷtahid wa-nihāyat al-muqtașid de Averroes, del modo siguiente: «El comienzo para quien se esfuerza por llegar a una interpretación personal y el fin para quien se contenta con un conocimiento adquirido de otros» ${ }^{34}$. Esta versión perifrástica sitúa el razonamiento jurídico en el núcleo de la actividad hermenéutica. Y esto es lo que hay que subrayar: que los avatares de la gramática en tiempos de los almohades han de considerarse a la luz de cómo los sabios musulmanes se sitúan ante el problema de la interpretación. Ibn al-Sīd, contemporáneo de Ibn Tūmart y alfaquí como él, desarrolló en profundidad la base común, hermenéutica, de las ciencias jurídicas y las filológicas en su Kitāb al-Tanbīh ${ }^{35}$. Y el propio Mahdī de los almohades abordó, en varios de sus escritos y adoptando la perspectiva y los fundamentos de los gramáticos, asuntos del interés de éstos, como las complejas relaciones entre lafz ('verba, expresión') y ma'nà ('res,

\footnotetext{
${ }^{34}$ Fierro, M., Al-Andalus: saberes e intercambios culturales, Barcelona, 2001, 29.

${ }^{35} \mathrm{Kitāab}$ al-Tanbìh 'alà l-asbāb allatī awŷabat al-ijtilāf bayn al-muslimīn fì arã’i-him wa-madāhibi-him wa-'tiqādāti-him, edición de Kahīl, A.Ḧ. y al-Našratī, H. 'A.A., El Cairo, 1982. Sobre esta obra de Ibn al-Sīd, v. Serrano, D. «Ibn al-Sìd al-Batalyawsī (444/1052-521/1227) y su obra sobre la discrepancia entre los musulmanes», en Soravia, B. y Sidarus, A. (eds.), Literatura e Cultura no Gharb al-Andalus (Actas del Simposio Internacional celebrado en Lisboa del 13 al 15 de abril de 2000), en prensa, y Peña Martín, S. y Vega Martín, M., «El ideal de claridad o los dos fines del $a d a b$ según Ibn al-Sīd», Al-Qantara XXV, 2 (2004), en prensa. Una traducción al español del libro de Ibn al-Sīd está en curso de preparación por Delfina Serrano.
} 
contenido'), o los mecanismos lingüísticos de la hermenéutica textual ${ }^{36}$.

Los problemas de la interpretación ofrecen, pues, una perspectiva adecuada para enfocar el estudio de la gramática bajo los almohades. Cuando Ibn Jarūf se atreve a incluir abiertamente unas palabras de al-Mutanabbī y les da valor de testimonio en la descripción de la lengua árabe «pura», la del Corán y las Mu 'allaqāt, no sólo está reconociendo el gran valor del poeta sirio, sino admitiendo la posibilidad de que individuos que no son árabes, que no son beduinos, que no son contemporáneos del apóstol Muhammad, puedan, una vez instruidos convenientemente, emitir actos de lengua aceptables. Esa misma perspectiva puede ser provechosa a la hora de valorar la contribución de Ibn Maḍā', quien, con su intento de simplificación, está lanzando una propuesta limitadora de la capacidad interpretativa de los sabios tardíos; oponiéndose, por así denominarla, a la corriente «humanística» (por su confianza en la razón humana y su apoyo en la crítica textual) que en al-Andalus representó a la perfección Ibn al-Sīd. Por otro lado, si el mismo patrón de pensamiento que plasma Ibn Jarūf lo trasladamos a la hermenéutica sacra y a la teoría del derecho, aparece ante nosotros, con toda claridad, el asunto esencial que plantea el título del libro de Averroes según la versión de M. Fierro. A saber, cómo es que lejos, en el tiempo y en el espacio, de la Arabia del apóstol Muhammad, pueden reelaborarse las ciencias y los discursos islámicos con tantas garantías como lo hicieron los primeros musulmanes. Sigue pendiente la cuestión de hasta qué punto los principios zāhiríes no avalarían precisamente, con su rechazo del argumento de autoridad de los doctores, el que hablantes tardíos o, en general, sabios tardíos adopten una posición activa en la elaboración los saberes islámicos. Pero esto ya excede, con mucho, de nuestros objetivos aquí, que han sido: 1) mostrar que la hermenéutica práctica (no la filosófica) y su aplicación social fue un ámbito privilegiado donde se jugaron algunas de las claves de la construcción cultural almohade; 2) que ésta se levantó en parte sobre elaboraciones realizadas en época almorávide, y 3) que la hermenéutica ha de ocupar un primer plano entre los elementos que manejemos al escribir la historia de la filología bajo los almohades.

36 V. Ibn Tūmart, Muhammad, $A$ 'azz mā yuṭlab, edición de Abū l-'Azm, 'A.G., Rabat, 1997, passim, especialmente, 60 y ss., y 284 y ss. 